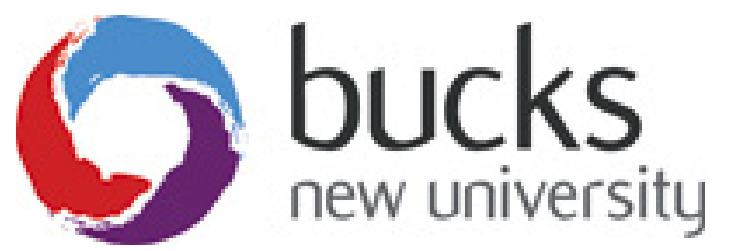

This is a pre-edited, author-produced version of an article accepted for publication in The British Journal of Social Work following peer review. The version of record is available online at: http://www.dx.doi.org/10.1093/bjsw/bcx161 


\title{
Integrating attachment theory into probation practice: a qualitative study.
}

\author{
Abstract \\ This research examined how a sample of English Probation Officers (POs) applied \\ attachment theory as they supervised service users. Using an action research \\ methodology over six months the research identified aspects that were readily \\ utilised (the idea that POs can sometimes represent a secure base figure, and that \\ attachment histories were significant). However, others offered little utility (the \\ concept of mentalization as a facility rooted in early attachment, and the \\ classification of attachment style). The reasons for this are explored, and the process \\ by which specialist research knowledge is applied by non-specialist practitioners is \\ considered.
}

Keywords: probation, attachment theory, secure base, attachment history, reflective function, mentalization, attachment style.

\section{Introduction}

Recent literature on probation practice In England and Wales has, arguably, been preoccupied by the restructuring of the Probation Service in 2014 into a smaller National Probation Service that works with high risk cases, and twenty-one Community Rehabilitation Companies (CRCs) that work with the rest. These worries are well founded, and recent research paints a picture of staff cuts, supervision by telephone rather than in person, and regular disruptions to supervision for operational reasons, particularly in the CRCs (McDermott, 2016; HMIP 2017). However, this article deliberately turns its focus onto a more perennial topic, that of the integration of theory - in this case attachment theory - into practice.

It could be argued that common ground between social work and probation work is so diminished that probation practice is irrelevant to a social work journal. That view is not being taken here. The professions may not have trained together for some years, but both still train in higher education. Based on the author's experience teaching both, there remains a good deal of commonality in their training (e.g. foundations based on sociology, psychology and social policy, methods such as motivational interviewing and cognitive behavioural principles, dominant themes such as risk). Social work journals continue to feature material on probation (e.g. Ansbro, 2015; Goldhill, 2015) even if the proportion has dropped (Raynor and Vanstone, 2015). Moreover, in Scotland and Northern Ireland qualified social workers continue to carry out the probation officer role. The essence of their task could be defined in very similar terms: to enable individuals to improve their circumstances. Therefore, in the author's opinion the similarities outweigh the 
differences, and the matter of utilising theory in practice is similar in social work and probation practice.

Like social workers, POs study a range of academic disciplines and theoretical orientations, and are expected to apply them eclectically. Attachment theory represents a small but significant element in the material they study, and is recommended as a valid theoretical framework (e.g. Ansbro, 2008). This research sought to examine how it is utilised in fast-paced, generic probation practice. Four themes were defined from the attachment literature, each potentially offering applications for POs' work. Although in reality they do not exist as entirely distinct themes, delineating them provided a clear structure to advance the research question.

The first theme was that the relationship between service user and PO potentially had attachment properties, so that POs could represent (to some extent) secure base figures. The carer-infant relationship is the original attachment relationship (Bowlby, 1969; 1980) but the concept is applied to relationships throughout the lifespan (Hazan and Shaver, 1987), conceptualised in adulthood as partly representational (Main et al, 1985). The concept has also been applied to professional relationships as well as personal ones. The psychotherapist as secure base is familiar (e.g. Bowlby, 1988; Berry and Danquah, 2016), but the notion has been stretched further. The staff of high security hospitals, along with the institution itself have been posited as secure bases for patients (Adshead, 1998), and similar assumptions have been made in the patient-doctor relationship (Frederiksen et al, 2010), and between pupil and teacher (Al-Yagon and Mikulincer, 2006).

The potential for attachment type qualities in the service user-PO relationship is usually taken for granted (Renn, 2002; Forbes and Reilly, 2011). However, at worst the concept can be diluted to the point of meaning any relationship, and this research sought to stay close to the theory. Proposals on the essential properties of attachment relationships in adulthood (Hazan and Shaver, 1987; Weiss, 1991; Cassidy, 1999) converge around the need for the relationship to be persistent, to be with a specific figure, to have emotional significance, and to relieve anxiety. Furthermore, the attached individual needs to seek contact with, and feel some distress at the loss of the secure base. Previous research using psychometric measures to detect the presence of attachment qualities in similar professional relationships has been equivocal (Schuengel and Van ljzendoorn, 2001; Harder et al, 2013), and so this project sought to explore qualitatively whether the concept of the secure base could be applied by POs to understand supervisory relationships, and whether attachment qualities were likely to grow in such relationships. 
The second theme was that of attachment history. Longitudinal and retrospective studies confirm the connection between attachment history and social and psychological development (e.g. Sroufe et al, 2010; Groh et al, 2012), and a substantial proportion of the Probation Service caseload is known to have experienced loss, abuse and neglect in their early lives (Williams et al, 2012) and to be personality disordered (Minoudis et al, 2012). Guidance from the Ministry of Justice (2011: 20) positions attachment theory 'at the core of our understanding of personality disorder', proposing that traits and behaviours, for instance impulsivity or substance misuse, can be partially understood as a result of early parenting, as can offences themselves, particularly when they are committed against victims with whom they are in relationships (e.g. Judd and Lewis, 2015). Ramsden and Lowton (2014: 148) wrote about the 'errors of logic' that probation staff commit if they forget the attachment histories of their clients, including the possibility that they are re-enacted within supervision with erratic reporting and inexplicable swings from idealization, clinginess to rejection.

Forbes and Reilly (2011: 15) considered how attachment theory could inform work on risk assessment and management, particularly when supervising individuals diagnosed with personality disorder who are 'frequently hostile and challenging in their responses to authority'. The suggestion is not that attachment theory brings any predictive powers to risk assessment, but that it offers a way of understanding service users with whom an alliance or common understanding cannot be arrived at, counterbalancing feelings of dislike or punitiveness. This research sought to explore how these ideas were used in practice.

The third theme for exploration was that of the reflective function (RF) and mentalization. Theoretically, security of attachment is an important ingredient in the growth of RF and the capacity to mentalize (Fonagy, 2004). On paper, this should be in short supply in Probation Service clients, as a disproportionate number are known to have lacked attuned, mind-minded care (Williams et al, 2012). The enhancement of the RF is described as a process occurring in all forms of psychotherapy, (Choi-Kain and Gunderson, 2008), more widely in supportive, change-inducing relationships, and potentially in any human encounter (Allen, 2006). The concepts are at the heart of Mentalization-Based Therapy (MBT), an approach to working with some forms of personality disorder (Bateman and Fonagy, 2007) So, whilst POs are not psychotherapists nor mental health workers, and their role does not include providing diluted MBT, they seem to be well positioned to help service users expand their mentalization capacity by asking them to describe events, thoughts and feelings and by providing different perspectives - all key aspects of mentalization work. 
The fourth area of exploration was whether attachment style made sense to the POs and their service users as recognisable strategies that had their roots in early care. Regularly promoted as a workable concept for social workers (Bifulco et al, 2008; Howe, 2011; Shemmings and Shemmings, 2011), discerning attachment style is also recommended as a useful technique in the criminal justice literature. For example, Renn (2002) has written about the links between childhood trauma, avoidant attachment and offending characterised by violence and substance misuse. Marshall (2010) has charted how group-work with those convicted of sexual offences increasingly identifies attachment deficits as a way of understanding emotional loneliness and problems with consenting adult relationships, and teaches the skills needed.

Structured classification systems are sometimes recommended (e.g. Baim and Morrison, 2011). However, the prevailing idea is usually that attachment style will be discernible from discussion and rumination (Holmes, 2001; Howe, 2011). Before starting the research it was impossible to know how attachment style was currently applied, so two approaches were provided, primarily to give POs examples of the concept in operation, but also so that they could try them out if they thought there was merit in doing so. These were Hazan and Shaver's three statements exercise (1987) based on the original three part model, and Berry et al's attachment styles questionnaire (2006), based on Fraley et al's (2000) dimensional model with four styles built around measures of avoidance and anxiety.

A neighbouring idea is that individuals' manner of narrating reveals their attachment style, and that the essence of the Adult Attachment Interview can be applied even if the full 'works' cannot. A professional relationship might then nudge narrative style towards a more secure state, so avoidant individuals are helped to amplify their emotional content, and preoccupied individuals helped to develop more lucid, less emotionally drenched accounts of their relationships. A successful outcome is an individual with a better integration of thought and emotion (Shemmings and Shemmings, 2011; Holmes, 2014).

The research set out to explore the utility of these four attachment based ideas in a probation setting; if attachment is just one theoretical paradigm amidst a 'formidable knowledge mountain' (Trevithick 2008: 1219) how useful are they in real practice?

\section{Methodology}

Permission to conduct the research was granted by the National Probation Service. Ethical approval was given by the Queens University Research Ethics Committee. POs 
in an urban area were invited by email to participate in a project examining the applications of attachment theory in practice, and six volunteers responded and were recruited. Qualified staff were used as it was reasonable to expect them to be integrating theory into their practice. Two induction meetings were held before the research commenced, to obtain written consent, and to ensure that the researcher and participants shared a broadly similar understanding of the main tenets of attachment theory. Three cases per participant were selected and it was emphasised that typical cases were sought, rather than those with unusual or extreme characteristics.

An action research methodology (McNiff, 1988) ensured that participants were research collaborators and experts on their own area, rather than subjects of scrutiny. It also allowed practice to be followed and reviewed across a series of iterations. Semi-structured interviews ensured consistency, yet allowed a degree of freedom. Each participant was interviewed monthly for six months, when cases were discussed holistically, and an interview schedule was followed to ensure that the key attachment based themes were examined. The recorded interviews were transcribed and thematically analysed.

Limitations of the methodology.

The sample was small as a significant amount of the researcher's time was spent with each participant (around thirteen hours each), and equally volunteers were made aware that considerable demands would be made on their time. Although representativeness is not pivotal in qualitative research, the sample may have been disproportionately interested in attachment theory and confident in their practice. There is the possibility that the thematic analysis was unconsciously biased towards perceiving attachment theory positively. Whilst impossible to disprove, the research design required ideas to be reflected on with reference to real cases over time, and where they did seem to offer some understanding or direction, that needed to be articulated and explained. Lastly, the research began with four central ideas already defined. Ideally participants would have been included in formulating them. However, real world exigencies were at play; volunteers might have been deterred, and the co-operation of the employing organisation exhausted.

\section{Findings}

All names have been changed to protect anonymity, and any identifying information either omitted or changed. The participating Probation Officers will be referred to as P01 through to P06. Taking each of the four themes in turn, there were clear differences in the POs' perceptions of their usefulness. 
The secure base

There was unanimous approval of the concept of the PO as a secure base, as a way of describing the type of relationship that some service users developed with their POs ('screamingly obvious' said one). For instance, Reg had murdered his wife and was recently released on parole after a long sentence. He had known PO1 over the last years of this sentence and now attended weekly appointments. However, he often phoned to arrange other appointments, or just to talk, having contact two or three times a week initially after release. When Reg came close to 'the edge' (speculated to be either a drug binge, suicide, or breaching a requirement forbidding contact with family), he sought out PO1. When situations blew up (e.g. hostel staff suspiciously sniffing a urine sample that had just tested negative) he went on a binge but then arrived at the probation office in a state of emotional disarray. He fretted that a restructuring might bring with it a change of PO. PO1 did not dress up this quality as therapy or counselling and the fact that she represented authority did not prevent it. Indeed, she set the frequency of the drug tests, and Reg knew this. In sum, Reg was displaying all of the characteristics of being attached. He sought out contact with PO1, her loss would have caused some distress, and their contact was important to help him regulate emotional extremes.

PO4 thought that Pete saw her as a secure base figure, and moreover speculated that his history of abuse and disrupted foster care meant that he saw secure bases as unreliable figures to be watchful of. This offered a useful perspective on his swings between openness and secrecy, and his patchiness in keeping appointments. (echoing Schuengel and Van Ijzendoorn, 2001; Berry and Danquah, 2016). PO5 similarly felt that she offered a secure base figure to Harry, an elderly and isolated man convicted of sexual offences, and valued the concept because it encapsulated a sense of being known. For her, the opportunity Harry had to recount the events that characterised his childhood years (mother disappearing, being taken into care, a series of institutions where he was both victim and perpetrator of sexual abuse) made PO5 significant for him:

It's useful...for a person to feel that they are known, and not judged, and that the things about them that they wouldn't tell people can be told. (PO3)

Siegel (1999) used the phrase 'feeling felt' to describe an essential property in primary childhood attachments and adult therapeutic ones. PO5 agreed that this captured the quality, although she did not describe her work as 'therapy', and relatively little time was spent discussing his past. Overall, it was just one strand of her work with Harry, which included working on his sexual attraction to boys, avoiding risky situations, and information sharing with the local police. 
Juxtaposed with other theoretical approaches, the secure base provided a useful framework for analysing some supervisory relationships. A humanistic perspective emphasises acceptance, respect and empathy (e.g. Lewis, 2014). The desistance literature sees the key ingredient of the relationship as a collaborative 'co-production of desistance' (Weaver, 2013), and uses adjectives such as 'non-judgemental' and 'committed' to describe the effective PO (Barry, 2007). Elsewhere, Probation Service staff are encouraged to form 'warm, open and enthusiastic' relationships (Rex and Hoskings, 2013: 333). An attachment perspective offers something qualitatively different; its notion of a secure base describes the potential for the PO to have an emotional salience, to be sought to assuage anxiety, and to enable exploration. The concept nudges up close to that of therapy or the 'working alliance' (Bordin, 1979), but, importantly, 'therapy' was a description that the POs rejected. In sum, the secure base concept had utility. Nevertheless there were still cases where it did not apply, but where productive work was still possible; requirements were complied with, useful referrals made and practical advice given, but the notion of a secure base was not relevant.

\section{Attachment history}

The POs' accounts of practice confirmed that service users had often grown up in violent families, without consistent care or protection. To a large extent, early histories also reflected the regular finding (e.g. Williams et al, 2012) that offender populations are likely to disproportionately come from socially disadvantaged groups, where the challenges to adequate parenting are considerable.

There was agreement that an attachment perspective helped to humanise those whose offences might militate against empathy, and to temper an impulse to be punitive or rule-bound. Beyond those two points of agreement applications of attachment history were individual to the case.

Kim was being supervised for an assault on her partner. Her late mother had been a drug user, and as a child Kim had fended for herself and her brother. Sometimes she was taken into care and sometimes she asked to be removed. Kim knew her father, and implored him to take her in when she went into care as a girl. He refused, as his priorities were with his new partner and children. PO6 made connections between Kim's attachment history and her later development. Kim valued herself little and was vulnerable to others who used her to commit offences. She felt at the mercy of a hostile world, without much order or predictability. It was entirely normal to tolerate violence in relationships. Her current relationship with her father was a contradictory mixture of care and abuse, sometimes nursing him but supplying him with the alcohol that was killing him, whilst simultaneously stealing his welfare 
payments. Bowlby could have been describing Kim's internal working model when he wrote of:

...an attachment figure to whom are attributed such characteristics as uncertain accessibility, unwillingness to respond helpfully, or perhaps the likelihood of responding hostilely (Bowlby, 1979: 140)

Put together it did not offer any easy solutions, but it ensured that PO6 tried to hold off returning her to Court for missed appointments, encouraging a kind of supervisory stoicism.

Attachment histories were seen as helpful in understanding later isolation, oddness, desperation and vulnerability. Reg recalled an apparently happy childhood until his mother had a baby as a result of an affair. In disgrace, she killed herself. What added to Reg's anguish was that he unwittingly assisted her suicide. His teens were spent offending and periodically in custody, and after one sentence he returned home to find his father had moved away. Reg later murdered his wife after she decided she wanted a divorce. When she refused to be persuaded back into the marriage, Reg drove their car into a wall; she died and he survived. The connection between his early experiences and the murder seemed obvious to PO1:

He was on self-destruct...when he committed the offence - he says he was overwhelmed by grief, his whole life was grief, for his mother, his family, huge amounts of loss, and loss that he's responsible for. (PO1)

PO1 thought it unlikely the murder would have happened had Reg's early family life been otherwise, but acknowledged that this was speculative.

Similar connections were made with other cases. Harry, now in his 70s, recounted an apparently happy early childhood. This ended abruptly when, soon after starting school, his mother left the family. His father told Harry that she was dead, and he never saw her again (although he later learned that she was alive). Soon after he was placed in a children's home, and he recalled the moment in Court when he realised his dad was not going to arrive. That moment stayed with him years later, and the abrupt abandonment by his father to institutional care seemed to flip the world from benevolent to hostile. Harry went on to spend most of his adult life in male run organisations (as a soldier, a mercenary and a group of fraudsters), where communication was in 'blokey cliches', and the mess of relationships avoided. Attachment history provided no perfect explanatory framework for PO5, but offered important partial insights. 
Attachment history also informed risk management. John was being supervised for brandishing a knife in public, but in the background there were acquittals for sexual offending against children and a suspected arson attempt. He had grown up partly with his mother and siblings, partly with grandparents, partly in care, and partly at a residential school where he recalled being raped. As a child he routinely tried to stop his depressed mother harming herself, and to protect her from his father's violence. His mother now swung between allowing him into the family home and banning him, and sometimes taunted him about his father's identity. PO2 described the collaborative process of linking early relationships and their sequelae with spikes in risk:

It impacts on risk...I try to do that with them...see if they can make links. How do you keep yourself safe? And if you get rejected by mum and dad will that make you angry, will that make you want to offend? It's him building his own protection. (PO2)

PO2 could have been paraphrasing the thoughts of Bowlby (1969) when he proposed that arousal, distress and threat activate the attachment system, and that is when violence is most likely. She was also putting into practice advice by Forbes and Reilly (2011:167) when they recommended:

...greater attention to an offender's attachment history as an essential part of the risk assessment process.

In these and other cases, attachment history put later lives and offences into a useful context. The connections were not made in a crude or reductionist way, there was no naive expectation that early experiences predicted later outcomes and POs were clear that they did not wallow in the past. That is quite congruent with research that posits insecure and disorganised attachments as factors that interact with others (Mikulincer and Shaver, 2007), asserts a complex relationship between attachment history and outcome, and acknowledges only a modest effect size between the two.

\section{RF and Mentalization}

The third suggestion was that service users might lack RF and the ability to mentalize, and so probation supervision could be an opportunity to facilitate this capacity. This had a mixed reception.

Of use was the notion that early self-soothing and affect regulation is learned through attachment, and without this the individual might be particularly prone to (violent) slips of mentalization. Carl's childhood was characterised by periods in care, alternating with periods at home, where he concentrated on watching out for his 
own and his mother's safety. He was now being supervised for assaults on his partner. For $\mathrm{PO} 3$ the possibility that as a child he had not experienced having his distress 'read' and allayed fitted:

It's the idea that babies start to be able to keep themselves together through their parenting, and if they don't learn the mechanisms to calm themselves down it can be because there was no one there making them feel secure and giving them that space. (PO3)

This was a model that fitted Carl's variability, moving from lucid and reflective one moment to volatile and unthinking the next, fitting the idea that mentalization is not a constant, but a facility that can slip as the arousal climbs (Fonagy et al, 2004).

However, the broader suggestions that offenders or certain sub-groups might lack $\mathrm{RF}$, and that probation supervision could improve mentalization were less well received. Firstly, there was resistance to the idea that RF was connected to early attachment, particularly when there were other possible explanations (e.g. a learning disability, Asperger's Syndrome, or circumstances that were so complicated that lucidly narrating was a genuine challenge). There was also sometimes an uncomfortable fit with POs values: '...it suggests that if you are abused it will make you unthinking...' (PO2)

Moreover, agreeing on what good/poor mentalization looked like was difficult. John was seeing both PO2 and the office mental health worker, who had undertaken some training in MBT. They compared their thoughts on his ability to mentalize and arrived at different conclusions. The mental health worker felt that John was fairly good at mentalizing, citing his ability to describe with affect a recent bereavement. PO2 took the opposing view, based on his fixedness when invited to think about the motives and intentions of others (e.g. a new girlfriend who he had never met but had sexted with). The difference in opinion was difficult to reconcile; the mental health worker seemed to place more importance on John's ability to access his own mind, and his emotional state, whereas PO2 seemed to be prioritising accessing other peoples' minds, and his cognitive state.

POs are unlikely to ever have the time or specialisation to use tools such as the RF scale (Fonagy et al, 1998), which measures RF based on Adult Attachment Interview transcripts. Neither is it realistic for them to use simpler psychometric tests (e.g. $\mathrm{Ha}$ et al, 2013). Their time is already occupied with other structured assessment tools, mainly to do with risk. However, if they were to, the evidence behind RF as a definable, measurable capacity is mixed. RF has been critiqued as an exceptionally broad concept (Choi-Kain and Gunderson, 2008; Katznelson, 2014), and an elusive 
thing to definitively identify and gauge, even when batteries of self-report and performance tests are used (Newbury-Helps, 2011). Moreover, the premise that RF is an important capacity to work on because certain populations lack it (e.g. those with personality disorder or prone to violence) is disputed (Tolfree, 2012; Adshead, 2013). In this respect, the POs' reluctance to pronounce on RF levels was congruent with the complex evidence.

As an aside, there are parallels here with debates in the criminal justice world on the subject of empathy. Although exercises to enhance empathy (particularly towards the victims of offences) are standard parts of group-work programmes in the criminal justice system, there is scant evidence to support the notion that offenders lack empathy, nor that working to expand it reduces recidivism (Jolliffe and Farrington, 2004), a sticking point that has been referred to as 'correctional quackery' (Mann and Barnett, 2012).

Finally, POs frequently observed that using labels such as RF or mentalization seemed to unnecessarily elevate something ordinary into a theoretically driven process. In principle, the suggestion that supervision could be an opportunity to encourage mentalization was agreed with, but it seemed that engaging service users in conversations where they were encouraged to identify and put into words what they were thinking and feeling, and to speculate about the mental state of others was an obvious thing to do. POs sometimes used language that expressed similar ideas ('concrete thinking', 'perspective taking', 'emotional intelligence'), and they seemed to serve the POs' purposes without the conceptual wooliness and the attachment luggage that goes with mentalization.

\section{Attachment style}

The fourth idea was that of attachment style, and this had the least utility of all. It seemed that the service users did not conform to any dominant style, and were more varied in their way of relating to others than any classification system would suggest. Moreover, when examined up close, the concept of attachment style was not as digestible as it seemed at a distance.

In her work with Bob on his domestic violence, PO6 was using an attachment styles exercise based on Bartholomew and Horowitz's typology (1991). This is part of a group-work programme designed by Ministry of Justice psychologists, but here was being delivered individually. PO6 experienced him as hungry to scrutinise his destructive relationships and the role drugs played, but Bob saw aspects of all classifications in himself and concluded that he was a mixture. PO6 emphasised the value in making connections between attachment history and subsequent 
development; Bob's father's had been violent and recruited him into organised violence and they agreed this left him constantly anticipating others as unreliable, and unable to use them as supports. It made sense to PO6 to see Bob's style of attaching as an adult through the dimension that ran from secure to insecure. However, figuring out a specific attachment style was not feasible or productive. Neither were Bob's style of narrating and reflecting theoretically congruent. In PO6's view he had ample supplies of the 'autobiographical competence' emblematic of a secure state of mind (Holmes, 2001), whereas in their discussions about his attachment style he had placed himself in various insecure styles.

When attachment style was considered without the use of structured exercises, there were equally few practical applications. When PO6 considered attachment style in relation to Kim, she was clear that no one style effectively described her, commenting 'she's a bit of everything...she ticks every box but no box...' (PO6). When it came to her style of narrating her family relationships she was sometimes distressed and the account disjointed, and there was sometimes a striking mismatch between the events being described and the emotional content. The possibility of lining up discourse with attachment style was discussed, for instance, connecting the confusion and high level of emotion to a preoccupied style, or the disconnect between event and emotion to a dismissing or unresolved adult attachment style. However, this line of thinking struck PO6 as tenuous and she was keen to speculate along less theoretical lines, for instance that laughing at bleak memories perhaps indicated how tragically normal such experiences were for her, distorting her whole emotional range. Viewing it as a probe into attachment style did not work for her.

This is not congruent with the abundant literature that suggests attachment style is a useful working tool (e.g. Howe, 2005, 2011; Holmes, 2001). On a superficial level attachment style is straightforward; pop psychology websites (e.g. 'Psychology Today') offer on-line quizzes to reveal a relationship style that is either avoidant, preoccupied or secure, and in attachment research there are connections made between attachment style and just about every aspect of the human condition.

However, in reality theoretical constructs are epistemologically messy. When considered more fully multiple models and measures crowd in. There is debate about stability of attachment style from childhood into adulthood (Goldberg, 2000), and the extent to which style is determined by parental care (Meins, 2013). Social psychologists view attachments as literal attachments to other people and classify attachment style using self-report tools (e.g. Hazan and Shaver, 1987), whereas developmental psychologists focus on internalised representations of attachments and use narrative interviews (e.g. Main et al, 1985). Then there are contrasting ways of conceptualising attachment style, ranging from a binary dimension between 
security and insecurity, a three-part A B C model (Ainsworth et al, 1978) or a fourpart A B C D model (Main and Solomon, 1990) - in which case how disorganised attachment translates into in adulthood becomes complicated (Rutter et al, 2009). Alternatively, there are four-part models based on axes of anxiety or avoidance (Fraley and Shaver, 2000), or a variation based on representations of self and other (Bartholomew and Horowitz, 1991). Then there is a 12-part dynamic model (Crittenden, 2000). Pietromonaco and Barrett (2000) have concluded that models emanating from the developmental perspective do not map precisely onto the models from the social perspective, and are probably measuring something subtly different. Add to that the debate as to whether attachment style should be viewed as a fixed number of categories, or dimensionally, in which case there are endless permutations, (Fraley and Spieker, 2003), and what starts off simply has become conceptually tricky.

These debates and ambiguities make it a fascinating area of study for specialists, but a potential minefield for genericists who need usable ideas for fast paced practice. Specialists have the luxury of one theoretical focus and can assimilate contradictions without losing sight of the main point. Holmes, for example, writes about attachment style in psychotherapy, but acknowledges that despite its research validity, in practice individuals 'show both avoidant and ambivalent patterns at different times and in different circumstances'. (Holmes 2001: 28). Rich has referred to this as a 'trade off between complexity and utility' (Rich, 2006: 120). Restricting attachment style to a one-sheet exercise (Bartholomew and Horowitz, 1991), or three short statements (Hazan and Shaver, 1987) misrepresents the idea as a simple one, denuded of all the complexities that make it interesting. This research provided the opportunity to talk about the concept in detail over time, but still the idea of attachment style did not grow into a useful piece of 'kit' for practice.

There has been similar debate on the way that attachment style is applied in child protection work. Granqvist et al (2016) identified a range of causes for disorganised attachment, including the stress of prior participation in the strange situation procedure itself. He was troubled by schemes to train social workers to identify disorganised behaviours, and to interpret those signs as evidence of abuse or neglect (e.g. Shemmings and Shemmings, 2011). Similarly he was concerned by the use of poorly validated attachment style tools to deem potential foster carers/adoptive parents as unsuitable (e.g. Bifulco et al 2008). Main et al (2011), considering the use of attachment theory in family court cases after divorce, similarly questioned how social workers arrive at conclusions regarding attachment style when properly validated tools have not been used. The practice situations vary, but they have in common disquiet about attachment style being utilised in practice in excessively deterministic and simplistic ways. 


\section{Conclusion}

The research illustrates how certain aspects of attachment theory were more readily applied than others. Conceptualising the practitioner as secure base, and assigning significance to attachment history added to the POs' practice, endorsing the importance of the relationship - with parents, carers, key figures and the probation supervisor themselves - in probation practice.

Ideas that were conceptually ambiguous and sat atop mixed evidence, however, did not easily map across into generic practice. The concepts of mentalization and attachment style, whilst vibrant areas for specialist researchers and clinicians, had less utility. There are various types of transmission gaps written about in the attachment literature, and Granqvist has proposed this as a new one, stating: 'the field faces a transmission gap between basic attachment research and application.' (2016: 532). In a probation setting where practitioners are not specialists, and where a smorgasbord of theory and knowledge can be drawn on, they seemed to cross over a threshold beyond which they lost utility. They were too complex, they were not unique enough from other ideas, or they just did not fit. 


\section{References}

Adshead, G. (1998). Psychiatric staff as attachment figures. British Journal of Psychiatry, 172, 64-69

Adshead, G. (2013). The role of mentalising in the management of violence. Advances in Psychiatric Treatment, 19, 67-76

Ainsworth, M.D.S., Blehar, M.C., Waters, E. and Wall, S. (1978). Patterns of attachment: A psychological study of the strange situation. New Jersey: Erlbaum

Allen, J.G. (2006). Mentalizing in Practice. In J.G. Allen and P. Fonagy (eds.) Handbook of Mentalization-Based Treatment. London: Wiley 3-30

Al-Yagon, M. and Mikulincer, M (2006). Children's appraisal of teacher as secure base and their socio-emotional and academic adjustment in middle childhood. Research in Education, $75(2) 1-18$

Ansbro, M. (2008). Using attachment theory with offenders. Probation Journal 55(3), 231-44

Baim, C. and Morrison, T. (2011). Attachment-based Practice with Adults: Understanding strategies and promoting positive change. Hove, Sussex: Pavilion Publishing

Barry, M. (2007). Listening and learning: the reciprocal relationship between worker and client. The Journal of Community and Criminal Justice, 54(4) 407-422

Bartholomew, K. and Horowitz, L.M. (1991). Attachment styles among young adults: A test of a model. Journal of Personality and Social Psychology, 61, 226-224

Bateman, A. and Fonagy. (2007). Mentalization-based treatment for borderline personality disorder: A practical guide. Oxford: Oxford University Press

Berry, K., Wearden, A., Barraclough, C. and Liversidge, T. (2006). Attachment styles, interpersonal relationships and psychotic phenomena in a non-clinical student sample. Personality and Individual Differences, 41, 707-718

Berry, K. and Danquah, A. (2016). Attachment -informed therapy for adults: Towards a unifying perspective on practice. Psychology and Psychotherapy: Theory, Research and Practice, 89, 15-32

Bifulco, A., Jacobs, C., Bunn, A., Thomas., G and Irving, K. (2008). The Attachment Style Interview (ASI) as an assessment of support capacity: exploring its use for adoption-fostering assessment. Adoption and Fostering, 32: 3, 33-45

Bordin, E. S. (1979). The generalizability of the psychoanalytic concept of the working alliance. Psychotherapy: Research and Practice 16(3) 252-60 
Bowlby J. (1969, republished 1999). Attachment and Loss (vol. 1): Attachment. London: Hogarth Press

Bowlby, J. (1979, republished 1989). The Making and Breaking of Affectional Bonds. Abingdon: Routledge

Bowlby J. (1980). Loss: Sadness and Depression. Attachment and Loss (vol. 3); (International psycho-analytical library no. 109). London: Hogarth Press.

Bowlby, J. (1988). A secure base: Clinical applications of attachment theory. Routledge, London

Cassidy, J. (1999). The nature of the child's ties. In J. Cassidy and P. R. Shaver (eds.) Handbook of attachment: Theory, research, and clinical applications, New York: Guilford Press. 3-20

Choi-Kain, L.W. and Gunderson, J.G. (2008). 'Mentalization: Ontogeny, assessment, and application in the treatment of Borderline Personality Disorder'. American Journal of Psychiatry, 165, 1127-1135

Crittenden, P.M. (2000). Introduction. In P.M Crittenden and A.H. Claussen (eds.) The organisation of attachment relationships; Maturation, culture and context. Cambridge: Cambridge University Press 1-10

Fonagy, P. (2004) The Developmental Roots of Violence in the Failure of Mentalization. In F. Pfafflin and G. Adshead (eds.) A Matter of Security: The Application of Attachment Theory in Forensic Psychiatry and Psychotherapy London: Jessica Kingsley 13-56

Fonagy, P., Target, M., Steele, H. and Steele, M. (1998). Reflective Functioning Manual Version 5. Sub-Department of Clinical Health Psychology, University College: London

Fonagy, P. Gergely, G. Jurist, E.L. and Target, M. (2004). Affect Regulation, Mentalization and the Development of the Self. London: Karnac

Forbes, D. and Reilly, S. (2011). Using Attachment Theory with Offenders' by Maria Ansbro. Probation Journal 58(2) 167-171

Fraley, C.R., and Shaver, P.R. (2000). Adult Romantic attachment: Theoretical developments, emerging controversies, and unanswered questions. Review of General Psychology 4 (2) 132154

Fraley, C. R., Waller, N., G. and Brennan, K.A. (2000). An item response theory analysis of self-report measures of adult attachment. Journal of Personality and Social Psychology, 78, 350-365 
Fraley, C.R. and Spieker, S. J. (2003). Are infant attachment patterns continuously or categorically distributed? A taxometric analysis of strange situation behavior. Developmental Psychology, 39, 387-404

Frederiksen, H.B., Kragstrup, J., Dehlholm-Lambertsen, B. (2010). Attachment in the doctorpatient relationship in general practice: a qualitative study. Scandinavian Journal of Primary Health Care 28(3) 185-190

Goldberg, S. (2000) Attachment and Development. London: Hodder

Granqvist, P., Hesse, E., Fransson, M., Main, M., Hagekull, B and Bohlin, G. (2016a). Prior participation in the strange situation and overstress jointly facilitate disorganized behaviours: implications for theory, research and practice. Attachment and Human Development 18(3) 235-249

Granqvist, P. (2016). 'Observations of disorganized behaviour yield no magic wand: response to Shemmings, Attachment and Human Development, 18:6, 529-533' Attachment and Human Development 18(6) 529-533

Groh, A.M., Roisman, G., Van ljzendoorn, M.H., Bakermans-Kranenburg, M.J. and Fearon, P.R. (2012). The significance of insecure and disorganized attachment for children's internalizing symptoms: A meta-analytic study. Child Development 83(2) 591-610

Ha, C., Sharp, C., Ensink, K., Fonagy P. and Cirino, P. (2013). The measurement of reflective function in adolescents with and without borderline traits. Journal of Adolescence 36, 12151223

Harder, A.T., Knorth, E.J. and Kalverboer, M.E. (2013). A secure base? The adolescent-staff relationship in secure residential youth care. Child and Family Social Work 18 305-317

Hazan, C. and Shaver, P.R. (1987). Romantic love conceptualized as an attachment process. Journal of Personality and Social Psychology 52, 511-524

Her Majesty's Inspectorate of Probation (2017) Quality and Impact Inspection: The Effectiveness of Probation work in Gloucestershire. Accessed 15/9/17 at https://www.justiceinspectorates.gov.uk/hmiprobation/wpcontent/uploads/sites/5/2017/08/Gloucestershire-QI-report.pdf

Holmes, J (2001). The Search for the Secure Base: Attachment theory and psychotherapy. Abingdon: Routledge

Howe, D. (2005). Child Abuse and Neglect: Attachment, Development and Intervention. Hampshire: Palgrave Macmillan

Howe, D. (2011). Attachment Across the Lifecourse: A Brief Introduction. Hampshire: Palgrave Macmillan 
Jolliffe, D. and Farrington, D.P. (2004). Empathy and offending: A systematic review and meta-analysis. Aggression and Violent Behavior, 9, 441-476

Judd, P. and Lewis, S. (2015). Working against the odds: How Probation practitioners can support desistance in young adult offenders. European Journal of Probation 7 (1) 58-75

Katznelson, H. (2014). Reflective functioning: A review. Clinical Psychology Review 34, $107-$ 117

Lewis, S. (2014). Exploring positive working relationships in light of the aims of probation, using a collaborative approach. Probation Journal 61(4) 334-345

Main, M., Kaplan, N. and Cassidy, J. (1985). Security in infancy, childhood and adulthood: a move to the level of representation. In I. Bretherton and E. Waters (eds.) Growing points in attachment theory and research (Serial No. 209) Monographs of the Society for Research in Child Development Vol. 50, 60-104

Main, M. and Solomon, G. (1990). Procedures for Identifying Infants as Disorganized/Disoriented during the Ainsworth Strange Situation. In M.T. Greenberg, D. Cicchetti and E.M. Cummings (eds.) Attachment in the Preschool Years: Theory, Research and Intervention. The John D. and Catherine T. MacArthur Foundation series on mental health and development. Chicago: University of Chicago Press 121-160

Main, M., Hesse, E. and Hesse, S. (2011). Attachment theory and research: Overview with suggested applications to child custody. Family Court Review, 49, 426-463

Mann, R.E. and Barnett, G.D. (2012). Victim Empathy Intervention with Sexual Offenders: Rehabilitation, Punishment or Correctional Quackery? Sexual Abuse: A Journal of Research and Treatment 25(3) 282-301

Marshall, L.E. and Marshall, W.L. (2010). Attachment and intimacy in sexual offenders: an update. Sexual and Relationship Therapy, 25(1), 86-90

McDermott, S. (2016) Probation without boundaries? 'Agile working' in the Community Rehabilitation Company 'transformed' landscape. Probation Journal 63(2) 193-201

McNiff, J. (1988). Action Research: Principles and Practice, Basingstoke: Macmillan

Meins, E. (2013). Sensitive attunement to infants' internal states: operationalizing the construct of mind-mindedness. Attachment and Human Development 15 (5-6) 524-544

Mikulincer, M. and Shaver, P.R. (2007). Attachment in adulthood: Structure, dynamics and change. New York: Guildford Press

Ministry of Justice (2011). Working with personality disordered offenders: A practitioner's guide. London: HMSO 
Minoudis, P., Shaw, J., Bannerman, A. and Craissati, J. (2012). Identifying personality disturbance in a London probation sample. Probation Journal, 59(1) 23-bordieu38

Newbury-Helps, J. (2011). Are difficulties in mentalizing associated with severity of antisocial personality disorder? Unpublished D.Clin,Psy. thesis, University College: London

Pietromonaco, P.R. and Barrett, L.F. (2000). The internal working models concept: What do we really know about the self in relation to others? Review of General Psychology 4(2) 15575

Ramsden, J. and Lowton, M. (2014). Probation practice with personality disordered offenders: The importance of avoiding errors of logic. Probation Journal 61(2), 148-60

Raynor, P. and Vanstone, M. (2007) Moving away from social work and half way back again: New research on skills in probation. British Journal of Social Work. 46(4), 1131-1147

Renn, P. (2002). The link between childhood trauma and later violent offending: The application of attachment theory in a probation setting. Attachment and Human Development. 4(3), 294-317

Rex, S. and Hoskings, N. (2013). A collaborative approach to developing probation practice: Skills for effective engagement, development and supervision (SEEDS). Probation Journal 60(3) 332-338

Rich, P. (2006). Attachment and Sexual Offending. Chichester: Wiley

Rutter, M., Kreppner, J. and Sonuga-Barke, E. (2009). Emanuel Miller Lecture: Attachment insecurity, disinhibited attachment, and attachment disorders: Where do research findings leave the concepts? The Journal of Child Psychology and Psychiatry 50 (5) 529-543

Schuengel, C. and Van ljzendoorn, M.H. (2001). Attachment in mental health institutions: A critical review of assumptions, clinical implications, and research strategies. Attachment and Human Development 3(3) 304-323

Shemmings, D. and Shemmings, Y. (2011). Understanding disorganized attachment: Theory and Practice for working with children and adults. London: Jessica Kingsley

Siegel, D. (first edition 1999, second edition 2012). The developing mind: How relationships and the brain interact to shape who we are. New York: Guildford Press

Sroufe, A., Coffino, B. and Carlson, E.A. (2010). Conceptualizing the role of early experience: Lessons from the Minnesota longitudinal study. Developmental Review 30, 36-51

Tolfree, R. (2012). Do difficulties in mentalizing correlate with severity of borderline personality disorder? Unpublished D.Clin.Psy thesis, University College: London 
Trevithick, P. (2008). Revisiting the Knowledge Base of Social Work: A Framework for

Practice. British Journal of Social Work 38, 1212-1237

Weaver, B (2013). Desistance, reflexivity and relationality: A case study. European Journal of Probation 53(3) 71-88

Weiss, J.S. (1991). The attachment bond in adulthood and childhood. In C. Murray Parkes, J. Stevenson-Hinde and P. Marris (eds.) Attachment across the life cycle. London: Routledge 66-76

Williams, K., Papadopoulou, V. and Booth, B. (2012). Prisoners' childhood and family backgrounds: Results from the Surveying Prisoner Crime Reduction (SPCR) longitudinal cohort study or prisoners. Ministry of Justice Research Series 4/12 